\title{
Impact Properties of Hybrid Fibre Reinforced Polymer Composite Laminates
}

\author{
Mohd Fadzli Bin Ismail, Aidah Jumahat
}

\begin{abstract}
The increasing demand for high-strength light-weight fibre reinforced polymer (FRP) composite materials has driven the researchers to further innovate and introduce hybrid reinforcement materials. The usage of hybrid FRP composite laminates in structural industries is still new and limited research has been reported in this area. Thus, this research is aimed to determine the impact properties of hybrid FRP composite laminate. The impact tests were carried out on three types of FRP composite laminates, i.e. Carbon, Glass and Hybrid, in order to determine the impact properties of the materials. The composite laminates were prepared using hot pressing method. It was found that the hybrid FRP composite laminate exhibited better impact properties with 13\% higher specific energy absorption when compared to the neat carbon FRP composite laminate. The impact test on hybrid FRP composite laminate recorded higher peak force, deflection at peak force and energy absorbed values of $109 \%, 71 \%$ and $25 \%$ respectively, when compared to the neat CFRP composite laminate.
\end{abstract}

Keywords : Impact Properties, Carbon Fibre Reinforced Polymer, Glass Fibre Reinforced Polymer, Hybrid Fibre Reinforced Polymer

\section{INTRODUCTION}

Generally, composite material is made up by combining two or more materials [1]. The advanced composite, which is widely used in industrial purposes, is fibre reinforced polymer (FRP) composite. The FRP composite or fibre reinforced plastic is made of continuous or chopped fibres and polymer matrix reinforcement. The types of fibres that normally used are glass, carbon, aramid and basalt, while the polymers are epoxy and vinylester or polyester thermosetting plastic [2]. Carbon fibre reinforced polymer (CFRP) composite is a strong, stiff and light-weight material that is made up of carbon fibre fabric or reinforcement and epoxy resin. The phase of reinforcing dispersion may be in the form of either continuous or discontinuous carbon fibres and commonly weaved into a cloth. Carbon fibres are expensive and have high specific mechanical properties, such as strength and elastic modulus. Carbon fibre has low density when compared to the other reinforcement fibres.

Revised Manuscript Received on January 30, 2020.

* Correspondence Author

Mohd Fadzli Ismail*, Faculty of Mechanical Engineering, Universiti Teknologi MARA, Cawangan Johor, Pasir Gudang, Johor, Malaysia.

Aidah Jumahat, Faculty of Mechanical Engineering, Universiti Teknologi MARA/Shah Alam, Selangor, Malaysia.

(C) The Authors. Published by Blue Eyes Intelligence Engineering and Sciences Publication (BEIESP). This is an open access article under the CC-BY-NC-ND license http://creativecommons.org/licenses/by-nc-nd/4.0/

Meanwhile, glass fibre reinforced polymer (GFRP) composite is made up of epoxy resin matrix reinforced with glass fibres. The glass fibre comes in various types, such as randomly arranged, flattened into a sheet (or also called as chopped, strand, or mat), or woven type. Glass fibre is not as strong and stiff as carbon fibre, but it is cheaper and less brittle compared to carbon fibre [3].

FRP composites are widely being used in various industries due to their unique properties especially high specific energy absorption. For instance, CFRP tubes demonstrated much better performance in energy absorption capacity compared with aluminium tubes [4]. In addition, the properties of high strength and stiffness, excellent corrosion resistance, good noise and damping vibration absorption, lightweight, easy to manufacture and repair have rendered FRP composites as well-known materials for high-end applications and the application keep increasing from time to time [5]. These materials have been used in almost every type of advanced engineering structures, such as aircraft, ships and offshore platforms, automotive, sports goods and civil infrastructure, buildings and bridges [6], [7]. For instance, FRP composites have reduced the usage of aluminium and steel boats by $10 \%$ to $35 \%$ weight. Moreover, it is also reported that the total weight of naval craft is reduced of up to $65 \%$ by replacing steel with FRP composites [5]. Besides that, FRP composites are desired in aircraft structures construction to replace the conventional aluminium because of their excellence resistance to corrosion and fatigue properties [8]. Thus, these excellence properties of FRP composites contribute to lots of advantage in various industries to operate at low cost without neglecting the important materials properties and safety issues.

The unique of FRP composites is the properties can be tailored with the desired application and working condition, in which it depends on the ingenuity of the designer. Usually, the properties can be tailored with the applications by combining various types of fibres together, in order to exploit the advantages of various properties. This has not been widely investigated. Hence, this research is aimed to determine the impact resistance of hybrid FRP composite laminates using drop weight impact tests.

\section{METHODOLOGY}

The research was conducted using two types of materials, which are $3 \mathrm{~K}, 2 \times 2$ twill weave carbon and 7781 e-glass prepregs. These prepregs material is already impregnated with epoxy resin (27\% to $33 \%)$

\section{Published By:}


as reported in the data sheet given by the manufacturer ("Product data sheet - Prepreg 3K, 2x2 Twill Weave Carbon," 2010;

"Product data sheet - Prepreg 7781 E-Glass," 2010). The prepregs were cut into square shape of $200 \mathrm{~mm}$ length. 16 layers of neat carbon, neat glass and hybrid of carbon and glass prepreg were stacked and placed in the hot press machine as shown in Fig. 1 for the curing process. The temperature of the hot press machine was set at $154^{\circ} \mathrm{C}$ for one hour soaking time. The cured hybrid FRP composite was removed from the hot press machine once the temperature of the material dropped to less than $66^{\circ} \mathrm{C}$.

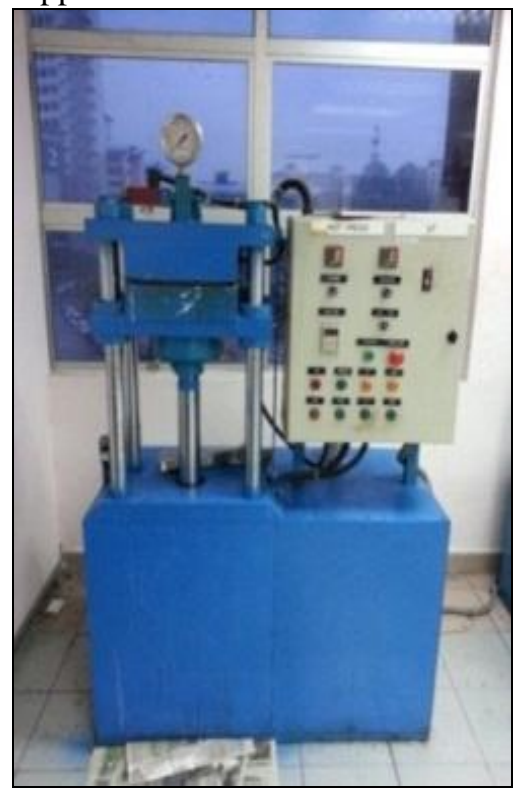

Fig. 1: Hot press machine with FRP curing setup

The specimens were cut into a size of $50 \mathrm{~mm}$ x $50 \mathrm{~mm}$ according to the low velocity impact test machine. Impact tests had been done using an Instron Dynatup 9250HV Drop Weight Impact Tester machine. A hemispherical steel tip impactor with a diameter of $12 \mathrm{~mm}$ was used to strike the specimens at a velocity of $6.7 \mathrm{~m} / \mathrm{s}$. The data of force, energy and time were recorded to analyze the impact behavior and properties of the specimens. In addition, optical microscope and CT-scan machine were used to identify the type of fibre breakage on the fractured specimens.

\section{RESULT AND DISCUSSION}

Typical load-deflection curves for neat CFRP, neat GFRP and hybrid FRP composite laminates systems are shown in Fig. 2. The curves of all laminates systems increased gradually to the peak load and then drop suddenly, showing a distinct failure developed in the specimens. The slope of the load-deflection curve represented the stiffness of the specimens, which is higher slope represented higher stiffness property. The neat CFRP composite laminate showed the highest slope (stiffness) and the neat GFRP composite laminate revealed the lowest slope (stiffness), while the slope (stiffness) of hybrid FRP composite laminate located in between the neat CFRP and GFRP composite laminates. The load of the neat CFRP composite laminate decreased uniformly, but the neat GFRP and hybrid FRP composite laminates showed a different rate of load decrement. This difference appears due to different material properties. The
CFRP composite (more brittle than the GFRP composite) failed by perforation or penetration of the specimens. Meanwhile, the GFRP composite (less brittle than the CFRP composite) failed by indentation and then followed by penetration of the specimens. Hence, two different slopes were observed for the neat GFRP and hybrid FRP composite laminates.

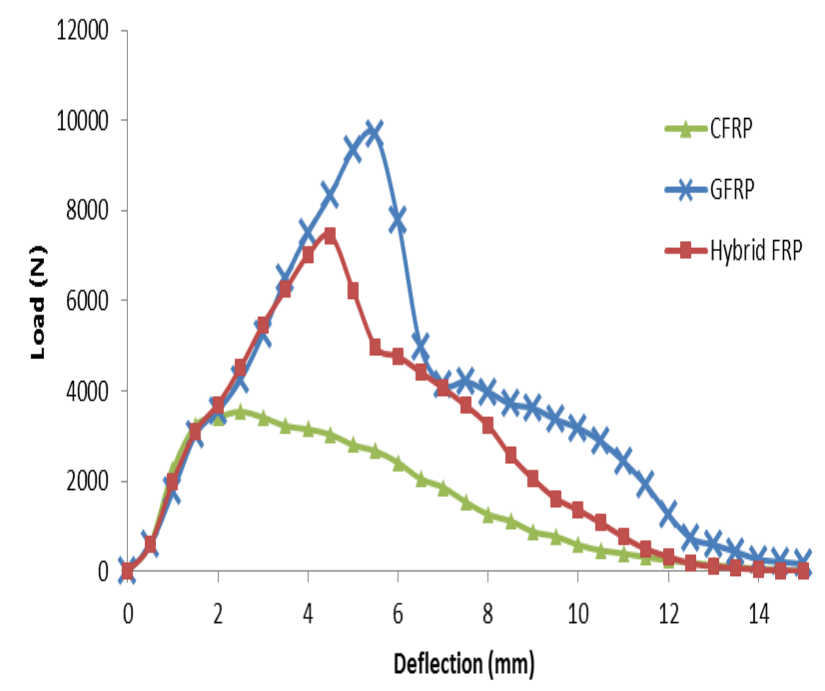

Fig. 2: Typical load-deflection curve of neat CFRP, neat GFRP and hybrid FRP composite laminates systems

Table I shows the average peak force, deflection at peak force and energy absorption of neat CFRP, neat GFRP and hybrid FRP composite laminates. The hybrid FRP composite laminate exhibited higher peak force, deflection at peak force and energy absorbed values of $109 \%, 71 \%$ and $25 \%$ respectively, when compared to the neat CFRP composite laminate. However, those values were lower than GFRP composite laminate with 23\%, $13 \%$ and $23 \%$ respectively. As can be seen, the CFRP composite has low peak force because it is a brittle material. Instead GFRP has far less brittle then CFRP, this ductile property of the GFRP composite resulted in higher impact resistance and peak force. The brittleness of the CFRP composite usually causes catastrophic fracture with low deflection due to impact loading and less energy is absorbed. On the other hand, the GFRP could deflect longer due to ductile property hence it absorbs more energy due to impact loading. Meanwhile, the hybrid FRP composite was crucially owing to the combined properties of both CFRP and GFRP, therefore this kind of material has higher fracture toughness and less brittle material when compared to pure CFRP system.

Table I The average peak force, deflection at peak force and energy absorbed of neat CFRP, neat GFRP and hybrid FRP composite laminates systems

\begin{tabular}{|c|c|c|c|}
\hline $\begin{array}{c}\text { Composite } \\
\text { Laminates }\end{array}$ & $\begin{array}{c}\text { Peak Force, } \\
\mathrm{kN}\end{array}$ & $\begin{array}{c}\text { Deflection at } \\
\text { Peak Force, } \\
\mathrm{mm}\end{array}$ & $\begin{array}{c}\text { Energy } \\
\text { Absorbed, } \\
\mathrm{J}\end{array}$ \\
\hline Neat CFRP & 3.58 & 2.69 & 17.80 \\
\hline Neat GFRP & 9.73 & 5.31 & 28.94 \\
\hline Hybrid FRP & 7.49 & 4.60 & 22.27 \\
\hline
\end{tabular}


Fig. 3 shows graph of specific energy absorption value and total time of neat CFRP, neat GFRP and hybrid FRP composite laminates systems. The results showed that the neat CFRP composite laminate exhibited the lowest specific energy absorption value of $1294 \mathrm{~J} / \mathrm{kg}$, when compared to the neat GFRP and hybrid FRP composite laminates. Whereas, the value of specific energy absorption for the neat GFRP and hybrid FRP composite laminates are slightly similar in range of 1462 to $1463 \mathrm{~J} / \mathrm{kg}$. The hybrid FRP and the neat GFRP composite laminates showed 13\% improvement of specific energy absorption when compared to the neat CFRP composite laminate. However, these two materials have lower specific energy absorption when compared to pure CFRP composite. The presence of glass fibre increased the total weight of the Hybrid FRP composite. It can be concluded that the properties of hybrid FRP composite was improved by possessing high specific energy absorption equal to that of the neat GFRP composite.

The neat CFRP, neat GFRP and hybrid FRP composite laminates took $3.3 \mathrm{~ms}, 4.9 \mathrm{~ms}$ and $3.2 \mathrm{~ms}$ total time, respectively, to complete the impact event as shown in Fig. 3. This means that hybrid FRP composite laminates exhibited the shortest impact time, followed by neat CFRP and GFRP composite laminates. However, the total impact time of all samples did not show any significant different because they were subjected to high impact velocity. From the results, it can be concluded that neat GFRP composite laminate was the best energy absorber material due to it has high specific energy absorption and longer impact time.

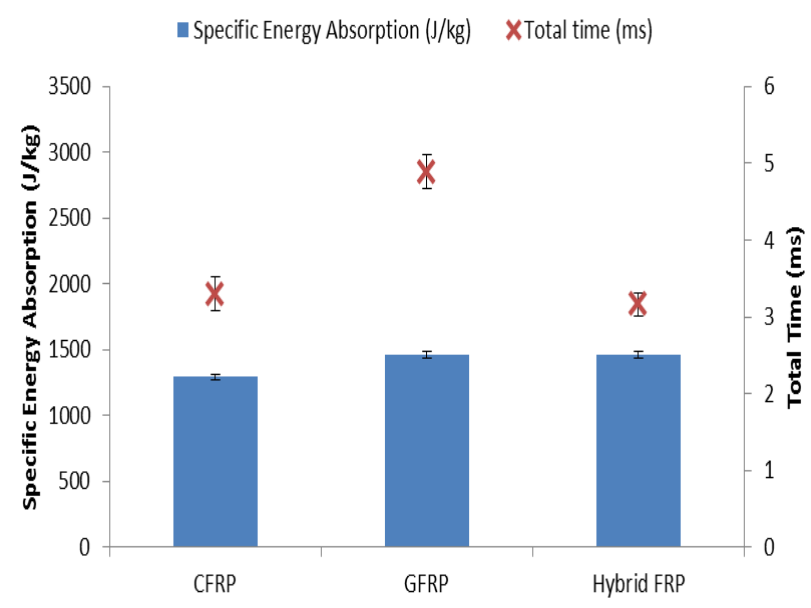

Fig. 3: Specific energy absorption value and total time of neat CFRP, neat GFRP and hybrid FRP composite laminates systems

Fig. 4 shows the fractured surface of neat CFRP, neat GFRP and hybrid FRP composite laminates when subjected impact loading. As can be seen, all composite laminates have been fully perforated or penetrated, but the failure modes are different among laminates. The neat CFRP composite laminate was penetrated in brittle manner. The fibre breakage occurred on the top of the CFRP composite laminate and the fibre splitting was seen at the bottom part of the laminate. While, in the neat GFRP composite laminate, the effect of local indentation was observed on the top of the composite, indicated that the GFRP composite was failed in a ductile mode. The bottom side of neat GFRP composite laminate showed fibre splitting and kink banding occurred during penetration. The brittle fracture (fibre breakage) of carbon fibre was observed on the top of the hybrid FRP composite laminate. Matrix cracking was also observed near the impact point of the hybrid FRP composite laminate. Fibre splitting and kink banding of the GFRP composite was identified on the bottom of hybrid FRP composite laminate.

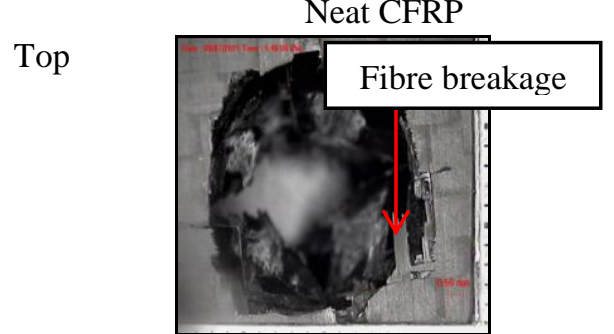

(a)

Bottom

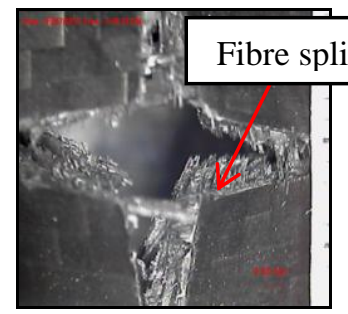

(b)

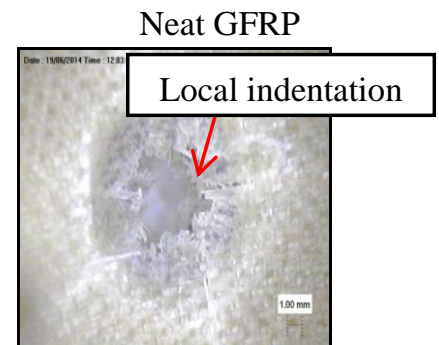

(c)

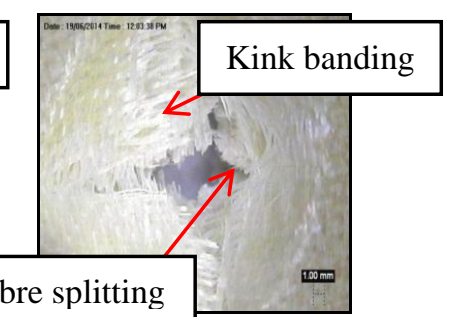

(e)

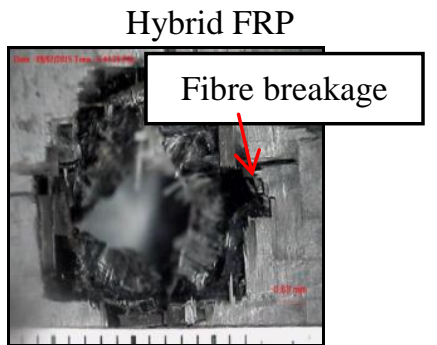

(e)

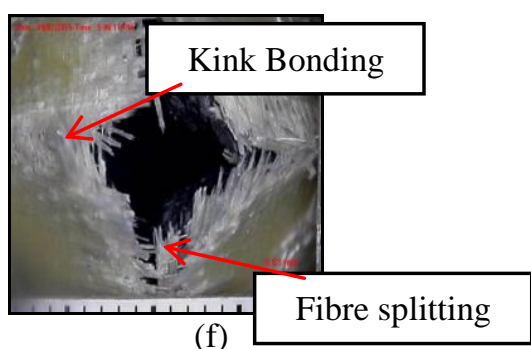

(f)

Fig. 4: The impacted specimen of neat CFRP, neat GFRP and hybrid FRP composite laminates 
Fig. 5 shows the CT-scan results of cross-section of neat CFRP, neat GFRP and hybrid FRP composite laminates. The micrographs show that the upper part of the neat CFRP composite laminate was broken off and the lower part showed fibre was stick together in its direction even it was fractured. Whereas, the entire neat GFRP composite laminate seem as kink banding of fibre. The laminate of the hybrid FRP composite showed that it was broken off at the upper part and kink banding at the lower part of laminate.

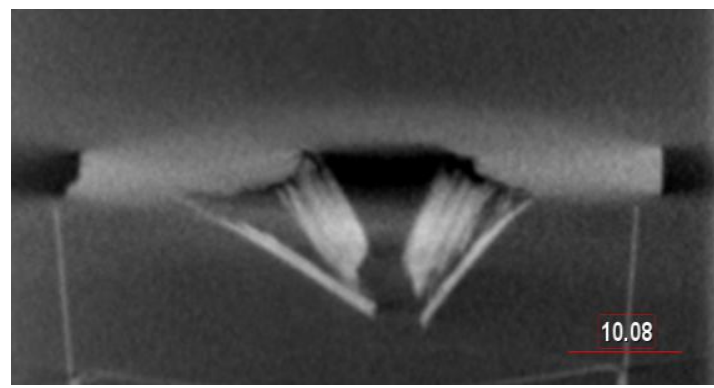

(a) Neat CFRP

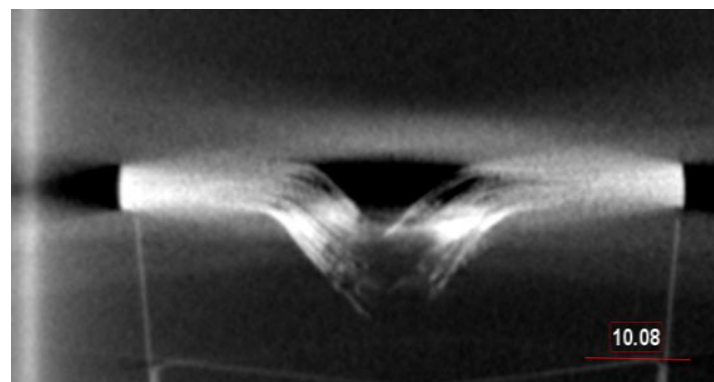

(b) Neat GFRP

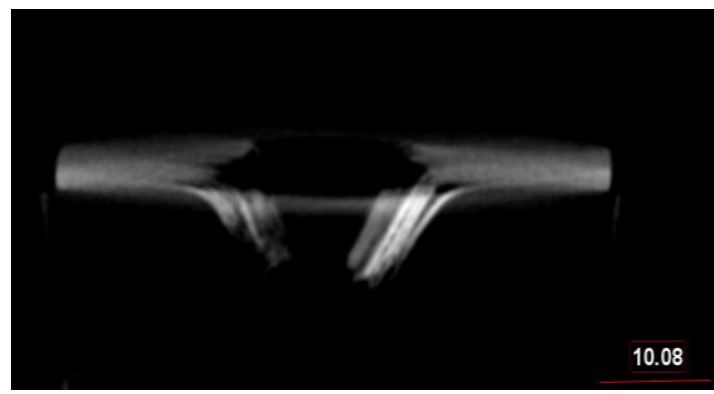

(c) Hybrid FRP

Fig. 5: The CT-scan results of cross-section of neat CFRP, neat GFRP and hybrid FRP composite laminates

\section{CONCLUSION}

Three types of FRP composite laminates were successfully fabricated using hot pressing method. Drop weight impact tests were carried out to determine the impact properties of the composite laminates and fracture behaviours was observed using optical microscope and CT-scan machine. The hybrid FRP composite laminate showed 13\% improvement of specific energy absorption and took a longer total impact time, when compared to the neat CFRP composite laminate. The combination of CFRP and GFRP in hybrid FRP composite laminates exhibited higher fracture toughness and less brittle material when compared to pure CFRP. In addition, the fractured surface of hybrid FRP showed combination of penetration of CFRP composite at the top side and indentation of GFRP composite at the bottom side.

\section{ACKNOWLEDGMENT}

The authors would like to thank the Universiti Teknologi MARA (UiTM), Ministry of Education Malaysia and Institute of Graduate Studies (IPSIS) for the financial supports. The research is performed at the Faculty of Mechanical Engineering, UiTM, Malaysia under the support of Fundamental Research Grant Scheme (FRGS) no: 600-IRMI/FRGS 5/3 (163/2019).

\section{REFERENCES}

1. Mazumdar, S. K. (2002). Composites Manufacturing: Materials, Product, and Process Engineering. CRC Press.

2. Reid, S. R., \& Zhou, G. (2000). Impact Behaviour of Fibre-Reinforced Composite Materials and Structures https://doi.org/10.1533/9781855738904.frontmatter

3. Hashim, U. R., Nordin, A. H., Jumahat, A., \& Ismail, M. H. (2014). Compressive properties of glass fibre reinforced polymer (GFRP) rod with aluminium foam core. Advances in Environmental Biology, 8(8), 2780-2785.

4. Liu, Q., Shen, H., Wu, Y., Xia, Z., Fang, J., \& Li, Q. (2018). Crash responses under multiple impacts and residual properties of CFRP and aluminum tubes. Composite Structures, 194(February), 87-103. https://doi.org/10.1016/j.compstruct.2018.04.001

5. K. Hossain, M., R. Chowdhury, M. M., A. Imran, K., B. Salam, M., Tauhid, A., Hosur, M., \& Jeelani, S. (2014). Effect of low velocity impact responses on durability of conventional and nanophased CFRP composites exposed to seawater. Polymer Degradation and Stability, 99, 180-189.

https://doi.org/http://dx.doi.org/10.1016/j.polymdegradstab.2013.11.00 $\underline{8}$

6. Saharudin, M. S., Jumahat, A., Kahar, A. Z. A., \& Ahmad, S. (2013) The influence of alumina filler on impact properties of short glass fiber reinforced epoxy. Applied Mechanics and Materials, 393, 88-93. https://doi.org/10.4028/www.scientific.net/AMM.393.88

7. Shaari, N., Jumahat, A., Yahya, K. H., \& Sulaiman, M. F. (2014) Impact resistance of woven fiber reinforced polymer composites. Advances in Environmental Biology, 8(8), 2662-2668.

8. Ramly, R., Kuntjoro, W., \& Abd Rahman, M. K. (2013). Embedded FBG sensor in aircraft smart composite materials for structural monitoring. Applied Mechanics and Materials, 393, 311-316. https://doi.org/10.4028/www.scientific.net/AMM.393.311

\section{AUTHORS PROFILE}

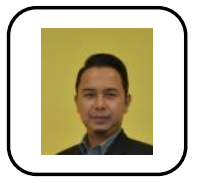

Mohd Fadzli Ismail received a Bachelor of Engineering Mechanical Engineering from the Universiti Teknolog Malaysia (UTM), Malaysia and Master in Mechanical Engineering from the Universiti Teknologi MARA (UiTM) in 2015. Currently, he is a lecturer at the Faculty of Mechanical Engineering, Universiti Teknologi MARA, Cawangan Johor, Malaysia. His main research of interest is sandwich panel and impact properties.

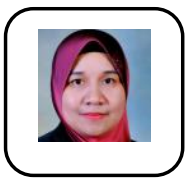

Dr. Aidah Jumahat has a PhD degree in Mechanical Engineering from the University of Sheffield United Kingdom, a MSc (Mechanical Engineering) degree and a B.Eng. (Hons.) Mechanical and Materials Engineering degree from the Universiti Kebangsaan Malaysia. She joined the Faculty of Mechanical Engineering UiTM as a lecturer in 2001. Currently, she is an Associate Professor at the Faculty of Mechanical Engineering and the Director at Community of Research Frontier Materials and Industrial Application (CoRe FMIA) at the Deputy Vice chancellor Office Universiti Teknologi MARA Shah Alam Selangor Malaysia. Her main research areas are polymers and Composites. 